\title{
Gas-Phase Observation of the Heterolytic Dissociation of Negative Ions into Counter Ions: Dissociation of [Cu phthalocyanine $\left.\left(\mathrm{SO}_{3}\right)_{4} \mathrm{Na}\right]^{3-}$
}

\author{
Sara Hashemi, Michael J. Y. Jarvis, and Diethard K. Bohme \\ Department of Chemistry, Centre for Research in Mass Spectrometry and Centre for Research in Earth and \\ Space Science, York University, Toronto, Ontario, Canada
}

Ion pair formation proceeding in solution at room-temperature, where it is driven by energies of solvation, has been observed in the gas-phase in the collision-induced dissociation of [Cu phthalocyanine $\left.\left(\mathrm{SO}_{3}\right)_{4} \mathrm{Na}\right]^{3-}$ and $\left[\mathrm{Cu} \text { phthalocyanine }\left(\mathrm{SO}_{3}\right)_{4} \mathrm{Na}_{2}\right]^{2-}$ at low energies. The gas-phase observation of these charge separations into positive and negative ions, seemingly counter-intuitive, is favored sufficiently by thermodynamics to proceed at low collision energies. The combination of a high stability of the negative product anion against electron detachment and a low recombination energy of the departing positive counter ion appears to be the key requirement for such dissociations to proceed at low energies in the gas-phase. (J Am Soc Mass Spectrom 2008, 19, 375-379) (c) 2008 American Society for Mass Spectrometry

$\mathrm{S}$ olution chemistry is often initiated or enhanced by the spontaneous dissociation of molecules (and ions) into counter ions. Such dissociations are thermodynamically driven by the preferential solvation of the counter ions, as is the case, for example, in the spontaneous dissociation of $\mathrm{NaCl}$ in aqueous solution into the counter ions $\mathrm{Na}^{+}$and $\mathrm{Cl}^{-}$. In contrast, the analogous dissociations of isolated molecules into counter ions in the gas phase, as generalized in reaction (1), are thermodynamically very unfavorable. They do

$$
\mathrm{AB} \rightarrow \mathrm{A}^{+}+\mathrm{B}
$$

however become more favorable as the ionization energy of $A, I E(A)$, decreases and the electron affinity of B, $\mathrm{EA}(\mathrm{B})$, increases.

Analogous heterolytic dissociations of anions into positive and negative counter ions, reaction (2) for a charge state of -1 , are not known or expected to occur

$$
\mathrm{AB}^{-} \rightarrow \mathrm{A}^{+}+\mathrm{B}^{2-}
$$

spontaneously in the gas-phase at room-temperature. Such dissociations, for which the enthalpy change $\Delta \mathrm{H}=$ $\mathrm{IE}(\mathrm{A})+\mathrm{D}\left(\mathrm{A}-\mathrm{B}^{-}\right)-\mathrm{EA}\left(\mathrm{B}^{-}\right)$in the absence of solvent, are intrinsically more favorable when $\operatorname{IE}(\mathrm{A})$ is low and $\mathrm{EA}\left(\mathrm{B}^{-}\right)$is high.

Elevated energies sufficient to cause dissociation are readily applied to ions of type $\mathrm{AB}^{-}$in the gas phase, for

Address reprint requests to Dr. D. K. Bohme, Department of Chemistry, Centre for Research in Mass Spectrometry and Centre for Research in Earth and Space Science, York University, Toronto, Ontario M3J 1P3, Canada. E-mail: dkbohme@yorku.ca example by collisions with neutral molecules when the ions are accelerated in a mass spectrometer. Dissociations induced by collisions in the gas phase [1] invariably lead to bond cleavage, reaction (3a), or electron detachment, reaction (3b), or, in the case of multiply charged anions of the type $\mathrm{AB}^{\mathrm{n}-}$, also to charge separation into two negative ions, reaction (4). This charge separation is driven by Coulombic repulsion, but must overcome an electrostatic kinetic barrier.

$$
\begin{aligned}
\mathrm{AB}^{-} & \rightarrow \mathrm{A}+\mathrm{B}^{-} \\
& \rightarrow \mathrm{AB}+\mathrm{e}^{-} \\
\mathrm{AB}^{\mathrm{n}-} & \rightarrow \mathrm{A}^{(\mathrm{n}-\mathrm{m})-}+\mathrm{B}^{\mathrm{m}-}
\end{aligned}
$$

We report here what we believe to be the first recorded observation of collision-induced charge separation of a multiply-charged anion into positive and negative counter ions in the gas phase, viz., a heterolytic cleavage of type 5 .

$$
\mathrm{AB}^{\mathrm{n}-} \rightarrow \mathrm{A}^{+}+\mathrm{B}^{(\mathrm{n}+1)-}
$$

We have found, quite serendipitously, a negative ion for which this gas-phase dissociation is favored by a low $\operatorname{IE}(\mathrm{A})$ and a high $\operatorname{EA}\left(\mathrm{B}^{\mathrm{n}-}\right)$. This ion, shown in Scheme 1 , is born in a solution of $\mathrm{Cu}$ (II) phthalocyaninetetrasulfonic acid tetrasodium salt $(60 \mu \mathrm{M})$ in $\mathrm{CH}_{3} \mathrm{CN} /$ $\mathrm{H}_{2} \mathrm{O}(1: 1)$ at room temperature and appears as the core ion [Cu phthalocyanine $\left.\left(\mathrm{SO}_{3}\right)_{4} \mathrm{Na}\right]^{3-}$ when the solution is electrosprayed [2]. 


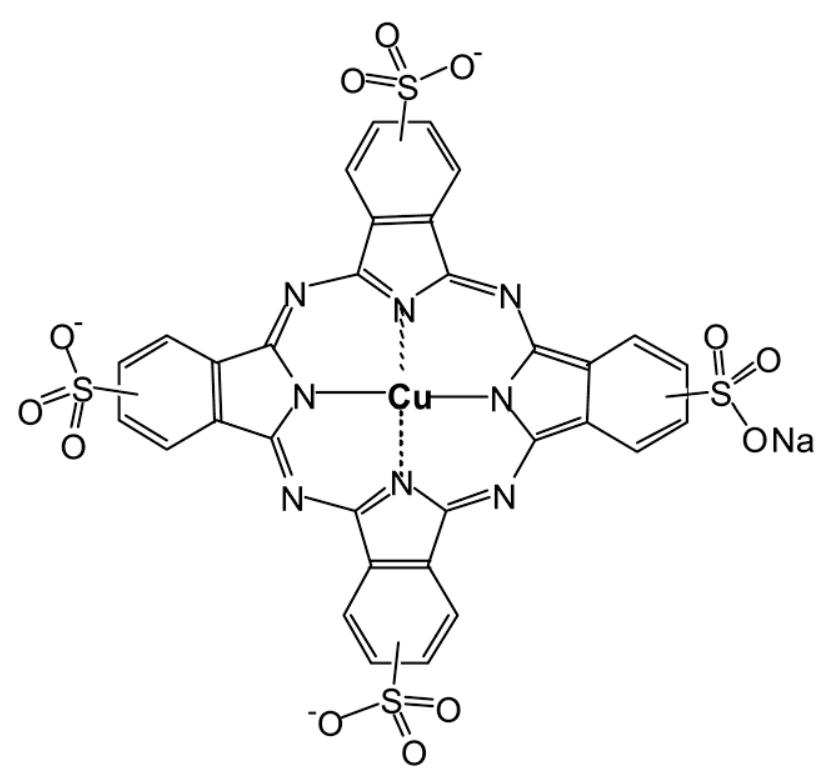

Scheme 1

\section{Experimental}

\section{Electrospray Mass Spectrometry}

Electrospray ionization mass spectrometry data were acquired using an API 2000 (MDS-SCIEX, Concord, ON, Canada) triple quadrupole mass spectrometer equipped with a "turbo ion spray" ion source. The mass spectrometer was operated in the negative ion mode at a potential of $4500 \mathrm{~V}$ at the ionization tip, a ring-electrode potential of $350 \mathrm{~V}$ and a range of declustering potentials applied between the orifice and the skimmer. $\mathrm{N}_{2}$ was used as a curtain gas at a setting of 10 psi, and air was used as a nebulizer gas at $10 \mathrm{~L} \mathrm{~min}^{-1}$. Solutions were introduced by direct infusion into the ion source at a flow rate of $4 \mu \mathrm{L} \mathrm{min}{ }^{-1}$.

MS/MS was carried out in product ion and multiple reaction monitoring (MRM) modes with $\mathrm{N}_{2}$ as collision gas with a pressure estimated to be $3 \mathrm{mTorr}$. The collision offset voltage [the potential difference between the quadrupole prefilter $\left(q_{0}\right)$ and the collision cell quadrupole $\left.\left(q_{2}\right)\right]$, which gives the laboratory frame collision energy, spanned from 0 to $130 \mathrm{~V}$ at $1 \mathrm{~V}$ intervals. Product ion spectra were obtained by scanning $\mathrm{Q}_{3}$ over the range of 10 to $1000 \mathrm{~m} / \mathrm{z}$. The interquadrupole lens potentials and the float potential of the resolving quadrupole $\mathrm{Q}_{3}$ were linked to the $\mathrm{q}_{2}$ potential, to maintain proper transmission through $\mathrm{Q}_{3}$.

\section{Preparation of Sample}

Copper (II) phthalocyanine-tetrasulfonic acid tetrasodium salt was obtained from Sigma Aldrich, St. Louis, MO (Dye content $\sim 50 \%$ ). HPLC grade acetonitrile and Millipore (Millipore, Billerica, MA) (18.2 m 2 ) water were used to prepare the solvent mixtures. The sample was dissolved in a 1:1 water/acetonitrile solution at a final concentration of between 20 and $60 \mu \mathrm{M}$.

\section{Results and Discussion}

The negative ion spectrum of the electrosprayed copper (II) phthalocyanine solution (Figure 1) is dominated by the presence of $\left[\mathrm{Cu} \text { phthalocyanine }\left(\mathrm{SO}_{3}\right)_{4}\right]^{4-}$ for which [Cu phthalocyanine $\left.\left(\mathrm{SO}_{3}\right)_{4} \mathrm{Na}\right]^{3-}$, shown in Scheme $\mathbf{1}$, is the likely precursor in solution.

When exposed to collisions with $\mathrm{N}_{2}$ molecules, the [Cu phthalocyanine $\left.\left(\mathrm{SO}_{3}\right)_{4} \mathrm{Na}\right]^{3-}$ ion is observed to dissociate at low collision energies solely by heterolytic cleavage to yield the quadruply-charged species [Cu phthalocyanine $\left.\left(\mathrm{SO}_{3}\right)_{4}\right]^{4-}$, and presumably the positive counter ion, $\mathrm{Na}^{+}$, as shown in the experimental collision-induced dissociation (CID) profile in Figure 2 and in reaction (6).

$$
\underset{(304.8)}{\left[\mathrm{CuPc}\left(\mathrm{SO}_{3}\right)_{4} \mathrm{Na}\right]^{3}} \rightarrow \underset{(\mathbf{2 2 2 . 8})}{\left[\mathrm{CuPc}\left(\mathrm{SO}_{3}\right)_{4}\right]^{4}}+\mathrm{Na}^{+}
$$

We believe this to be the first reported observation of the dissociation of a negatively-charged anion into positive and negative counter-ions in the gas phase.

At slightly elevated collision energies, the loss of $\mathrm{Na}^{+}$from the parent ion becomes a minor channel, and the [Cu phthalocyanine $\left.\left(\mathrm{SO}_{3}\right)_{4} \mathrm{Na}\right]^{3-}$ ion is observed to dissociate primarily by electrostatically-driven charge dissociation, reactions (7a) to (7c), or by loss of a neutral, reaction $(7 \mathrm{~d})$.

$$
\begin{aligned}
& {\left[\mathrm{CuPc}\left(\mathrm{SO}_{3}\right)_{4} \mathrm{Na}\right]^{3-} \rightarrow\left[\mathrm{CuPc}\left(\mathrm{SO}_{3}\right)_{3} \mathrm{Na}\right]^{2-\cdot}+\mathrm{SO}_{3}^{-}} \\
& \text {(304.8) } \\
& \text { (417.2) } \\
& \text { (80) } \\
& \rightarrow\left[\mathrm{CuPc}\left(\mathrm{SO}_{3}\right)_{3} \mathrm{ONa}\right]^{2-\cdot}+\mathrm{SO}_{2}^{-} \\
& \text {(425.2) } \\
& \text { (64) } \\
& \rightarrow \underset{(433.2)}{\left[\mathrm{CuPc}\left(\mathrm{SO}_{3}\right)_{3} \mathrm{O}_{2} \mathrm{Na}\right]^{2-.}}+\mathrm{SO}^{--} \\
& \text {(48) } \\
& \rightarrow\left[\mathrm{CuPc}\left(\mathrm{SO}_{3}\right)_{3} \mathrm{ONa}\right]^{3-}+\mathrm{SO}_{2} \\
& \text { (283.4) }
\end{aligned}
$$

The apparent heterolytic dissociation into the counter ions $\mathrm{Na}^{+}$and $\left[\mathrm{CuPc}\left(\mathrm{SO}_{3}\right)_{4}\right]^{4-}$, reaction (6), was a surprise to us since the products must overcome Coulombic attraction as they separate. However, this channel is likely favored at low collision energies since it is a barrierless process. In contrast, charge separation reactions must overcome an electrostatic kinetic barrier. This phenomenon is illustrated qualitatively in Figure 3.

In light of the novelty of the observation of gas-phase dissociation of an anion into positively- and negativelycharged counterions, we have made every attempt to eliminate the possibility of an alternative source for the quadruply-charged product ion at $\mathrm{m} / \mathrm{z} 222.8$. The identity and charge state of the $\mathrm{m} / \mathrm{z} 222.8$ product ion has been confirmed based on the observed isotopic pattern. To rule out the possibility that any of this quadruplycharged ion is "leaking through" the first quadrupole mass filter, a CID "blank" was performed in which the collision gas was switched off and the "fragmentation 


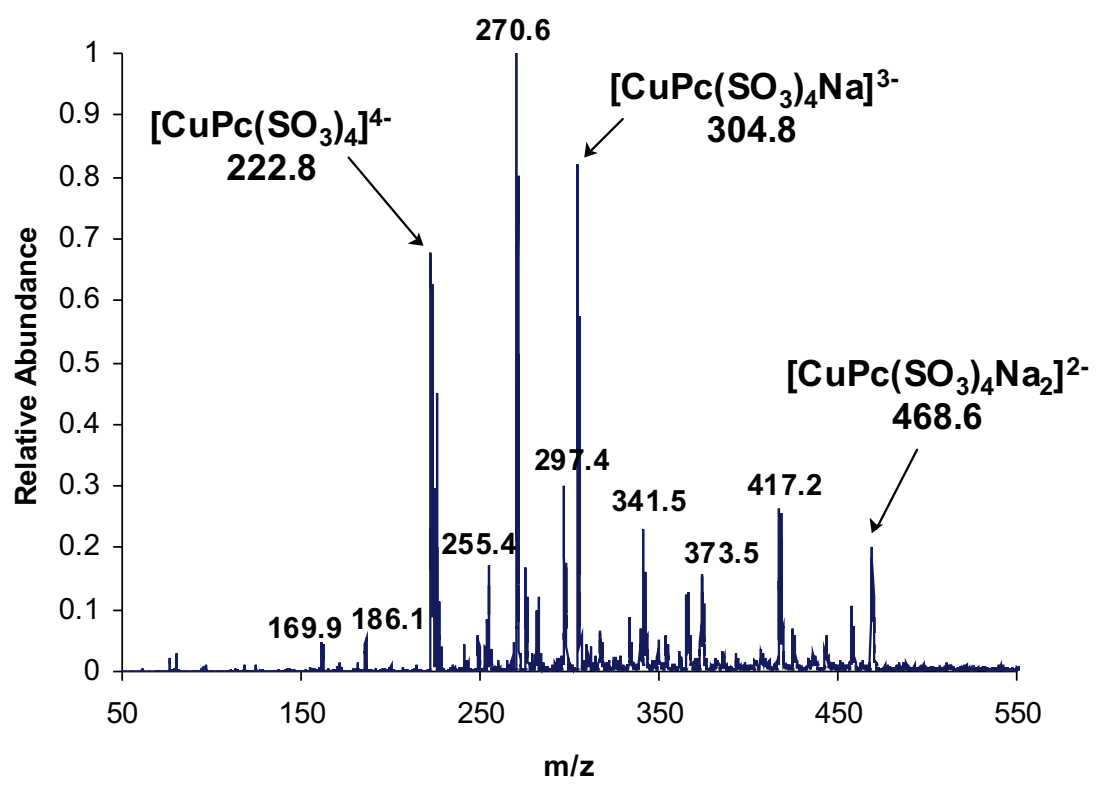

Figure 1. Negative electrospray ionization mass spectrum of $60 \mu \mathrm{M} \mathrm{Cu}$ (II) phthalocyaninetetrasulfonic acid tetrasodium salt in 1:1 acetonitrile and water solution, on the MDS SCIEX API 2000 triple quadrupole, at a declustering potential DP $=50 \mathrm{~V}$. The unsodiated $\left[\mathrm{CuPc}\left(\mathrm{SO}_{3}\right)_{4}\right]^{4-}$ ion is observed at $m / z 222.8$, while singly- and doubly-sodiated $\left[\mathrm{CuPc}\left(\mathrm{SO}_{3}\right)_{4} \mathrm{Na}_{1,2}\right]^{3-, 2-}$ ions are observed at $\mathrm{m} / \mathrm{z} 304.8$ and 468.6 , respectively. The large peak at 270.6 is assigned to the loss of $\mathrm{SO}_{3}^{-}$from the quadruply-charged ion at $\mathrm{m} / \mathrm{z} 222.8$.

products" of $\left[\mathrm{CuPc}\left(\mathrm{SO}_{3}\right)_{4} \mathrm{Na}\right]^{3-}$ were monitored with the second quadrupole mass filter. None of the $\mathrm{m} / \mathrm{z}$ 222.8 quadruply-charged ion was observed, nor was any ion other than the parent at $\mathrm{m} / \mathrm{z} 304.8$. This experiment indicates that the $\mathrm{m} / \mathrm{z} 222.8$ ion must be the dissociation product of an ion with $\mathrm{m} / \mathrm{z}$ near 305. A comparison of the "blank" experiment with a sample CID at a collision energy of $10 \mathrm{~V}$ is given in Figure 4 .

An alternative route was considered for the formation of the $\mathrm{m} / \mathrm{z}=222.8$ ion from a quadruply-charged impurity ion with $\mathrm{m} / \mathrm{z}$ close to the selected triplycharged precursor ion at $m / z=304.8$. To address this concern, a high-resolution $\mathrm{Q} / \mathrm{q} / \mathrm{TOF}$ instrument was used to investigate the possible presence of a quadruplycharged impurity ion in the vicinity of $\mathrm{m} / \mathrm{z} 305$, but no such impurity was found. Furthermore, we have performed additional CID experiments in which the $\mathrm{m} / \mathrm{z}$ $304.8\left[\mathrm{CuPc}\left(\mathrm{SO}_{3}\right)_{3} \mathrm{Na}\right]^{3-}$ ion was generated indirectly via dissociation of its solvent clusters in the collision cell. In so doing, we eliminated the possibility that an impurity ion in the vicinity of $\mathrm{m} / \mathrm{z} 305$ was the source of the $\mathrm{m} / \mathrm{z} 222.8$ product ion. In these experiments, water and acetonitrile clusters of the $\mathrm{m} / \mathrm{z} 304.8\left(\left[\mathrm{CuPc}\left(\mathrm{SO}_{3}\right)_{3} \mathrm{Na}\right]^{3-}\right)$ ion were selected by the first quadrupole and CID performed in the collision cell yielded the triply-charged $\left[\mathrm{CuPc}\left(\mathrm{SO}_{3}\right)_{3} \mathrm{Na}\right]^{3-}$ ion, which dissociated further as expected to yield product ions according to reactions (6) and (7) (see Figure 5).

For the CID of the water and acetonitrile clusters, we observed that the onset voltages for the appearance of the product ions are shifted higher by $\sim 8$ to $10 \mathrm{~V}$ compared with the CID of the unsolvated
$\left[\mathrm{CuPc}\left(\mathrm{SO}_{3}\right)_{3} \mathrm{Na}\right]^{3-}$ ion. It is worth noting that a precursor ion scan showed that at low collision energies the $\mathrm{m} / \mathrm{z} 304.8\left(\left[\mathrm{CuPc}\left(\mathrm{SO}_{3}\right)_{3} \mathrm{Na}\right]^{3-}\right)$ ion and its water and acetonitrile clusters are all sources of the quadruplycharged $\left[\mathrm{CuPc}\left(\mathrm{SO}_{3}\right)_{4}\right]^{4-}$ ion at $\mathrm{m} / z$ 222.8. In our estimation, these experiments conclusively demonstrate that the triply-charged $\left[\mathrm{CuPc}\left(\mathrm{SO}_{3}\right)_{4} \mathrm{Na}\right]^{3-}$ ion at $\mathrm{m} / \mathrm{z} 304.8$ is

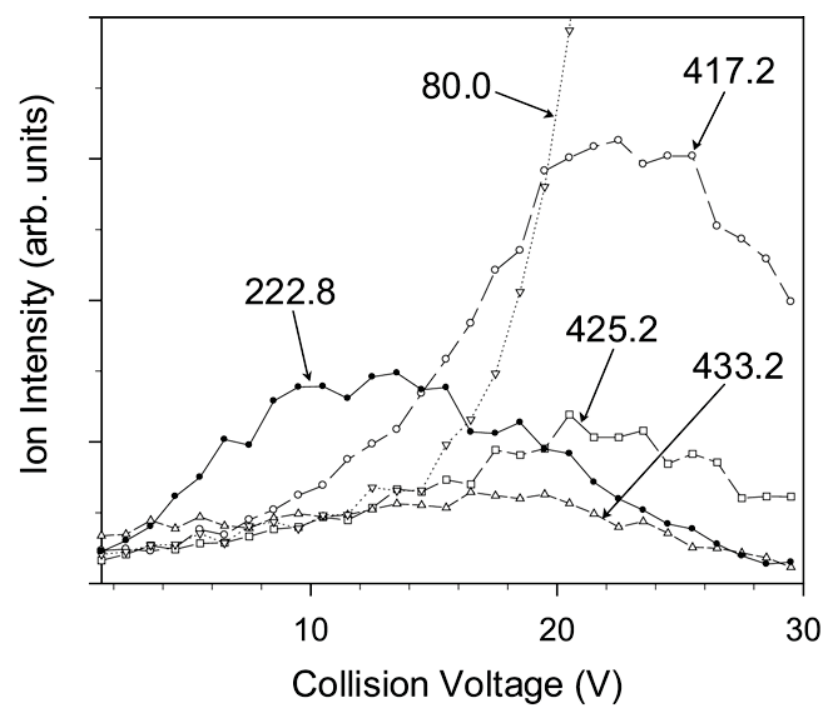

Figure 2. CID profile for the appearance of the dissociation products of $\left[\mathrm{CuPc}\left(\mathrm{SO}_{3}\right)_{4} \mathrm{Na}\right]^{3-}(\mathrm{m} / \mathrm{z} 304.8$, not shown), generated by negative electrospray ionization from a $20 \mu \mathrm{M}$ solution of $\mathrm{Cu}$ (II) phthalocyanine-tetrasulfonic acid tetrasodium salt in 1:1 acetonitrile and water. Product ions with low intensities have not been included in the profile. 

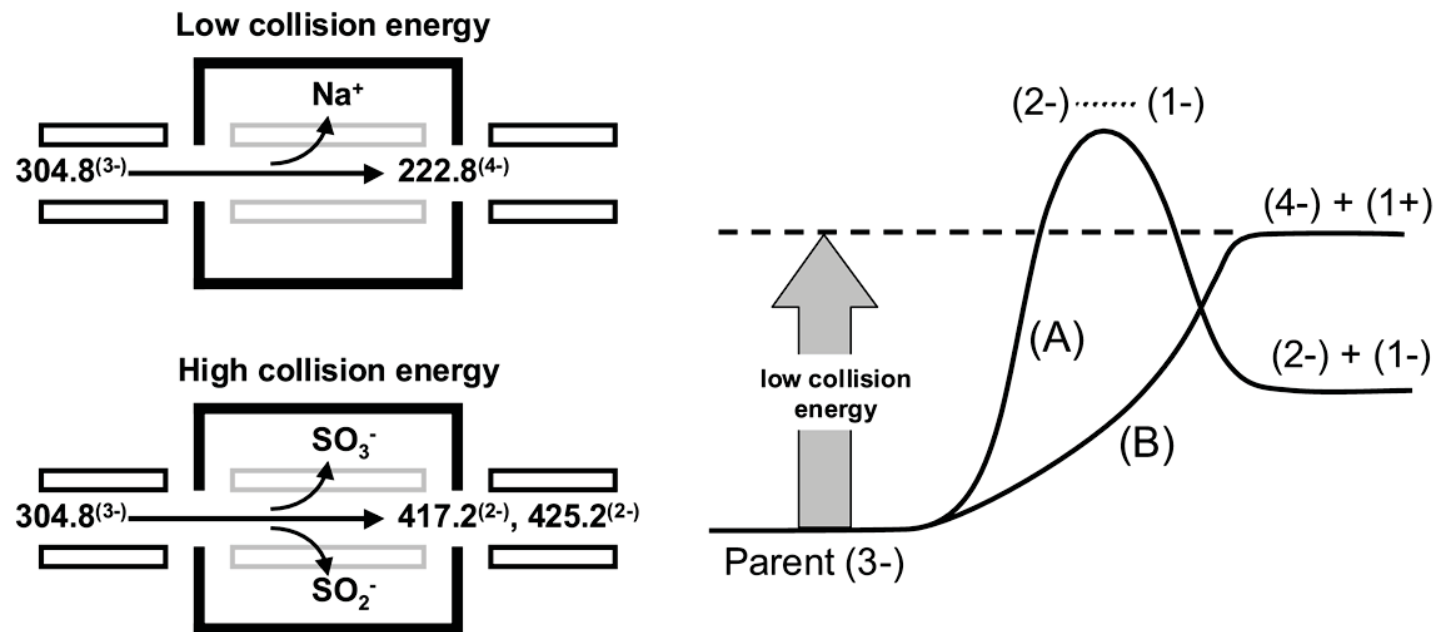

Figure 3. Illustration of the collision-energy dependence of the fragmentation of [ $\mathrm{Cu}$ phthalocyanine $\left.\left(\mathrm{SO}_{3}\right)_{4} \mathrm{Na}\right]^{3-}$. The charge separation of the triply-charged parent ion into singly- and doubly-charged fragments (Channel A) is thermodynamically favored, however at low collision energies this process is not observed due to the presence of an electrostatic kinetic barrier. The barrierless dissociation of the triply-charged parent ion into positive $(1+)$ and negative $(4-)$ counter-ions (Channel B) is more endothermic, however this channel is dominant at low collision energies.

a source of the quadruply-charged product ion at $\mathrm{m} / \mathrm{z}$ 222.8 .

In addition, our observation of an analogous dissociation with $\left[\mathrm{CuPc}\left(\mathrm{SO}_{3}\right)_{4} \mathrm{Cs}\right]^{3-}(\mathrm{m} / z$ 341.5) would require the unlikely presence of two Cu-containing impurity ions with different compositions, having $\mathrm{m} / \mathrm{z}=$ 304.8 and 341.5, respectively.

Exploratory CID experiments with selected $\left[\mathrm{CuPc}\left(\mathrm{SO}_{3}\right)_{4} \mathrm{Na}_{2}\right]^{2-}$ also revealed the occurrence of the heterolytic dissociation reaction (8) (followed by the dissociation reaction (7)).

(a)

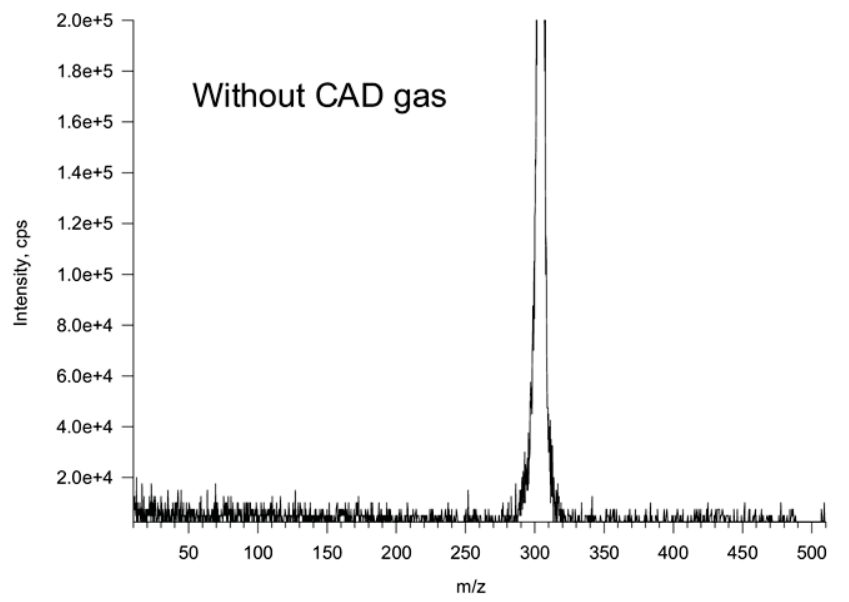

$$
\underset{(468.6)}{\left[\mathrm{CuPc}\left(\mathrm{SO}_{3}\right)_{4} \mathrm{Na}_{2}\right]^{2-}} \rightarrow \underset{(304.8)}{\left[\mathrm{CuPc}\left(\mathrm{SO}_{3}\right)_{4} \mathrm{Na}\right]^{3-}}+\mathrm{Na}^{+}
$$

Of interest now is the influence of other alkali-metals and the central metal on dissociations of this type and these will be investigated soon.

We were able to find only one previous report of the observation of a gain in charge during CID. Sobott et al. have reported the gain of positive charge during CID of multiply positively-charged noncovalent protein com-

(b)

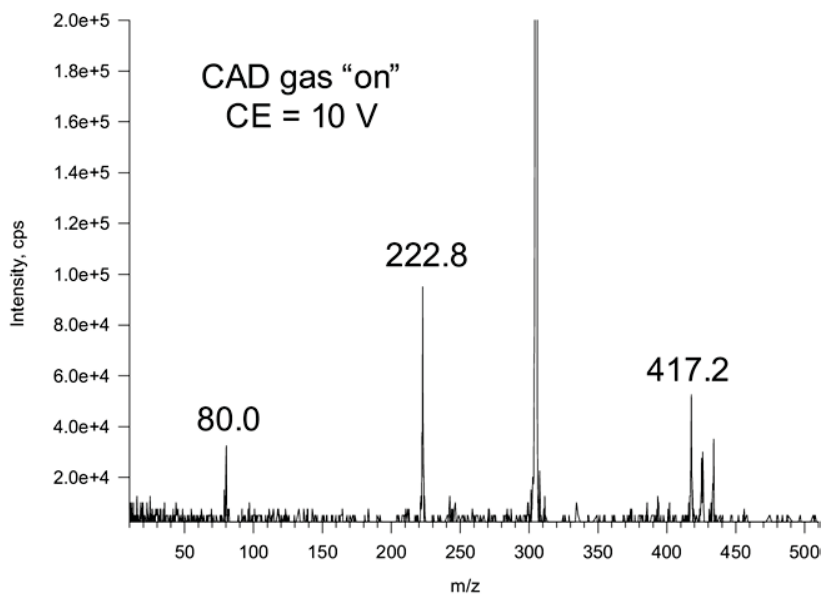

Figure 4. (a) CID "blank": The $\left[\mathrm{CuPc}\left(\mathrm{SO}_{3}\right)_{4} \mathrm{Na}\right]^{3-}$ ion is selected by the first quadrupole mass filter, and the "fragmentation products" are monitored by the second quadrupole mass filter, with the collision gas turned "off". (b) Sample CID of $\left[\mathrm{CuPc}\left(\mathrm{SO}_{3}\right)_{4} \mathrm{Na}\right]^{3-}$ at a collision energy of $10 \mathrm{~V}$. The largest product observed is the quadruply-charged ion at $m / z 222.8$, resulting from the dissociation of the parent ion into counter-ions. Also present are the doubly-charged product ions at $m / z 417.2,425.2$, and 433.2, resulting from the charge separation of the parent ion. 


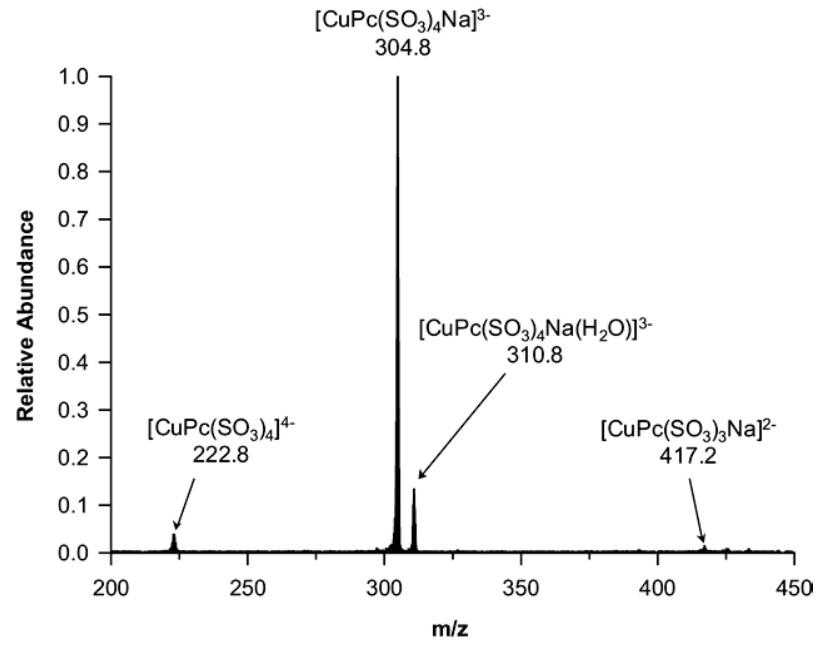

Figure 5. $10 \quad \mathrm{~V} \quad \mathrm{CID}$ spectrum of $\mathrm{m} / \mathrm{z}=310.8$ $\left(\left[\mathrm{CuPc}\left(\mathrm{SO}_{3}\right)_{4} \mathrm{Na}\left(\mathrm{H}_{2} \mathrm{O}\right)\right]^{3-}\right)$, a precursor of $\mathrm{m} / \mathrm{z}=304.8$ $\left(\left[\mathrm{CuPc}\left(\mathrm{SO}_{3}\right)_{4} \mathrm{Na}\right]^{3-}\right)$, generated by negative electrospray ionization from a $50 \mu \mathrm{M}$ solution of $\mathrm{Cu}$ (II) phthalocyanine-tetrasulfonic acid tetrasodium salt in 1:1 acetonitrile and water. The loss of neutral $\mathrm{H}_{2} \mathrm{O}$ is followed by additional losses of $\mathrm{Na}^{+}$and $\mathrm{SO}_{3}^{-}$from the $\left[\mathrm{CuPc}\left(\mathrm{SO}_{3}\right)_{4} \mathrm{Na}\right]^{3-}$ product ion.

plexes which they attribute to the loss of an attached negative counter ion such as the acetate anion [3]. Also, it is interesting to note that an analogous process for the dissociation of a positive ion, reaction (9), has been suggested as a possible source for the production of doubly-charged ions in the electronimpact ionization of bis-benzyl tetrahydroisoquinolines [4], 1,3,5-trichlorobenzene [5], and 6,6-diphenyl2,4-pentadienyliden-1 [5].

$$
(\text { Parent })^{+} \rightarrow(\text { Fragment })^{2+}+(\text { Anion })^{-}
$$

\section{Conclusions}

The $\left[\mathrm{Cu} \text { phthalocyanine }\left(\mathrm{SO}_{3}\right)_{4} \mathrm{Na}\right]^{3-}$ ion has been produced by electrospray ionization and found to dissociate in the gas phase primarily by homolytic cleavage leading to charge separation and the loss of $\mathrm{SO}_{3}^{-}$and $\mathrm{SO}_{2}^{-}$. The predominant dissociation pathway observed corresponds to charge separation via homolytic cleavage to form $\mathrm{SO}_{3}^{-}$. The other major channel leads to charge separation and $\mathrm{SO}_{2}^{-\cdot}$ formation, perhaps via loss of $\mathrm{SO}_{2}$ that was also observed, but accompanied by intramolecular electron transfer. An unexpected heterolytic cleavage into counter ions, including $\mathrm{Na}^{+}$, also was observed at relatively low collision energies for both [Cu phthalocyanine $\left.\left(\mathrm{SO}_{3}\right)_{4} \mathrm{Na}\right]^{3-}$ and $[\mathrm{Cu}$ phthalocyanine $\left.\left(\mathrm{SO}_{3}\right)_{4} \mathrm{Na}_{2}\right]^{2-}$. The combination of a low recombination energy of the product cation and a high stability of the more negative product anion against electron detachment appears to be the key requirement for such dissociations to proceed at low energies in the gas phase. Furthermore, at low energies this type of reaction is kinetically favored over charge separation reactions, owing to the absence of a barrier. These same dissociations become spontaneous in solution at room temperature through the higher energy of solvation of the product counter ions compared with that of the dissociating anion.

\section{Acknowledgments}

The authors greatly appreciate continued financial support from the Natural Sciences and Engineering Research Council of Canada. They also acknowledge support from the National Research Council, the Natural Science and Engineering Research Council, and MDS SCIEX in the form of a Research Partnership grant. They thank Bruce Thomson for performing the high-resolution Q/q/ TOF experiment. As holder of a Canada Research Chair in Physical Chemistry, DKB thanks the Canada Research Chair Program for its contributions to this research.

\section{References}

1. (a) Cooks, R. G., Ed.; Collision Spectroscopy; Plenum: New York, 1978; p. 357. (b) Armentrout, P. B., Collision-Induced Dissociation. In The Encyclopedia of Mass Spectrometry, Vol I, Armentrout, P. B., Ed.; Elsevier: Oxford, UK, 2003; p 426.

2. Yamashita, M.; Fenn, J. B. Negative Ion Production with the Electrospray Ion Source. J. Phys. Chem. 1984, 88, 4671-4675.

3. Sobott, F.; McCammon, M. G.; Robinson, C. V. Gas-Phase Dissociation Pathways of a Tetrameric Protein Complex. Int. J. Mass Spectrom. 2003, 230, 193-200.

4. Mandelbaum, A.; Bel, P. Mechanism of Formation of Doubly Charged Fragments from bis-Benzyl Tetrahydroisoquinoline Derivatives Under Electron Impact. Adv. Mass Spectrom. 1980, 8A, 828-831.

5. Seibl, J. Charge Separation and Ion-Pair Formation in Cations Subsequent to Electron-Impact. Org. Mass Spectrom. 1969, 2, 1033-1035. 